•生物编目・

\title{
海南岛腔轮科种类组成与区系分布
}

\author{
黄丰明 吴秋婷 韩博平 林秋奇 ${ }^{*}$ \\ (暨南大学水生生物研究所, 广州 510632)
}

\begin{abstract}
摘要: 为系统分析海南岛腔轮虫的种类组成及其地理分布特征, 我们于 2010 年 11 月、 2011 年 5 月和 8 月用 $35 \mu \mathrm{m} 孔$ 径 的浮游动物网采集了海南岛134个水体的腔轮虫样品。采集的水体类型包括水库、河流、池塘、小溪、水稻田和 小型临时水体。共检出腔轮虫 42 种和 1 个亚种。其中, 中国新记录种 9 种, 即马氏腔轮虫(Lecane margalefi)、唐纳腔 轮虫(L. donneri)、优美腔轮虫(L. elegans)、坤杜里腔轮虫 (L. kunthuleensis)、侧生腔轮虫(L. lateralis)、暗小腔轮虫 (L. pusilla)、褶皱腔轮虫 (L. rhytida)、柔弱腔轮虫 (L. subtilis) 和波纹腔轮虫(L. undulata); 东洋界新记录种4种, 即尖 爪腔轮虫( L. cornuta)、玫瑰腔轮虫 (L. rugosa)、柔弱腔轮虫和马氏腔轮虫; 东洋界特有种1种: 坤杜里腔轮虫。霊 形腔轮虫 (L. bulla)、尖角腔轮虫 (L. hamata)、尾片腔轮虫(L. leontina)、月形腔轮虫 (L. luna)、新月腔轮虫(L. lunaris)、 凹顶腔轮虫 (L. papuana)、梨形腔轮虫 (L. pyriformis) 和四齿腔轮虫 (L. quadridentata) 最为常见。海南岛腔轮虫呈现 高的多样性, 并主要由广生性种类、泛热带种类、全热带种类和一些间断分布种类和东洋界特有种类组成。种类 多样性高于我国华南地区, 但低于同处东洋界的泰国; 海南岛与泰国的种类组成的Jaccard和Sørensen相似性系数 (0.44和0.61)均高于与华南地区的相似性系数 $(0.20$ 和 0.46$)$ 。没有特有种发现。
\end{abstract}

关键词: 腔轮虫; 多样性; 海南岛

\section{Species diversity and distribution of Lecanidae on Hainan Island, China}

Fengming Huang, Qiuting Wu, Boping Han, Qiuqi Lin ${ }^{*}$

Institute of Hydrobiology, Jinan University, Guangzhou 510632

\begin{abstract}
We sampled 134 localities on Hainan Island and investigated rotifer fauna from 2010 to 2011, which to analyze the species composition and geographical distribution. The water types include reservoir, river, pond, brook, rice field and temporary pond. Forty-two species and one subspecies of the genera Lecane were identified. Lecane margalefi, L. donneri, L. elegans, L. kunthuleensis, L. lateralis, L. pusilla, L. rhytida, $L$. subtilis and $L$. undulata were identified as new to China, and L. cornuta, L. rugosa, L. subtilis and L. margalefi were new to the Oriental Zone. Lecane bulla, L. hamata, L. leontina, L. luna, L. lunaris, L. papuana, L. pyriformis and $L$. quadridentata were the most common species in this genus. The diversity of Lecane was high on Hainan Island, which was composed of cosmopolitan taxa, tropicopolitan taxa, pantropical taxa, disjunctive distributed taxa and one endemic Lecane in the Oriental Zone: L. kunthuleensis. Diversity of Lecane was much higher on Hainan Island than in southern China, but lower than Thailand. The composition of Lecane was more similar to Thailand than to southern China.
\end{abstract}

Key words: Lecane; diversity; Hainan Island

腔轮科属轮形动物门单巢纲游泳目, 只包含腔 轮属一属, 广泛分布于河流、水库和湖泊的沿岸带 以及水稻田和池塘等浅水水体或临时性水体中, 所 有种类营底栖生活。腔轮属(Lecane) 是轮虫种类多 样性比较高的属之一, 全球近 $1 / 10$ 的轮虫种类来自
该属(Segers, 2007)。一般而言, 热带地区腔轮虫种 类多样性高于温带地区(Dumont, 1983; Segers, 1996, 2001)。腔轮虫的起源地目前尚不清楚, 虽然广布性 种类较多，但在各地理分区均有特有种的分布，而 且在东半球和西半球的分布特征有所不同(Segers,

收稿日期: 2016-12-21; 接受日期: 2017-02-16

基金项目: 国家自然科学基金(31170437)

* 通讯作者 Author for correspondence. E-mail: tlinqq@jnu.edu.cn 
1996)。在东半球，热带地区间(包括东洋界、旧热带 界和澳洲界) 的腔轮属种类组成相似性程度较高, 但热带地区与温带地区(古北界)间的相似性程度相 对较低; 在西半球, 腔轮虫种类组成在新热带界和 新北界间的相似性程度高于东半球的热带地区与 温带地区间的相似性程度。腔轮虫种类的地理分布 格局与东、西半球主要山脉走向的不同有一定的关 系。在东半球, 温带地区与热带地区间的山脉为东 西走向, 在一定程度上阻止了热带地区和温带地区 间种类的交流; 在西半球, 温带地区与热带地区间 的山脉是南北走向, 热带地区和温带地区间种类的 交流相对容易(Segers, 1996)。

海南岛是中国的第二大岛, 北隔琼州海峡与广 东省的雷州半岛相对; 西濒北部湾, 与越南遥遥相 望。海南岛原是中国大陆向南延伸的一部分, 自更 新世(距今 250 万年前 -1.5 万年前)中期, 由于频繁的 火山运动与雷州半岛断陷, 之后与大陆多次分合, 直到第四纪冰期结束才形成一个独立的岛屿, 与华 南大陆有着不可分割的“母子关系”和相同的地质构 造(颜家安, 2006)。海南岛作为我国最大的热带岛屿, 是中国乃至世界研究生物多样性网络的热点地区 之一(Myers et al, 2000; Chen \& Bi, 2007), 地史上与 大陆这种连、断、再连、再断的变化是否导致海南 岛与华南大陆存在频繁的物种交流? 腔轮虫种类 组成与华南地区是否呈现高的相似性? 是否与其 他热带地区一样呈现高的种类多样性? 是否有特 有种的分布? 诸葛燕(1997)、Koste和Zhuge (1996) 在1995年初步调查了海南岛的腔轮虫, 鉴定到31种 和 1 个亚种。但他们采集的样点较少, 且集中在海 口、琼海和三亚 3 个地方, 获得的腔轮虫数据难以全 面反映海南岛腔轮虫的种类组成及地理分布特征。 因此, 为了能更系统地了解海南岛腔轮虫的多样性, 并探讨其地理分布模式, 我们在其研究的基础上, 扩大采样范围和水体类型, 在全岛范围内采集了腔 轮虫样品。

\section{1 材料与方法}

于 2010 年 11 月沿海南岛东线和中线经海口 市、文昌市、琼海市、万宁市、陵水黎族自治县、 三亚市、保亭黎族苗族自治县、五指山市、琼中黎 族苗族自治县、屯昌县、澄迈县等 11 个县市, 用 35 $\mu \mathrm{m}$ 孔径的浮游动物网采集了沿途的水库、河流、池
塘、小溪、水稻田以及包括小型临时性水体在内的 43 个水体的轮虫样品; 2011 年5月沿着相同路线, 共 采集了 85 个水体的轮虫样品; 2011 年 8 月在海口 市、定安县、万宁市、保亭县、三亚市和儋州市采 集了 6 个水体的轮虫样品。现场将样品分别用 $4 \%$ 的 福尔马林固定, 并用YSI-85型水质仪测定水温和 $\mathrm{pH}$ 。两年共采集轮虫样品 134 个, 其中包括 3 个水库 (松涛水库、福万水库和赤田水库) (水温: $25-31^{\circ} \mathrm{C}$, 平均 $28^{\circ} \mathrm{C} ; \mathrm{pH}: 7.2-7.8$, 平均 7.4)、13个河流(什木 河、南渡江、龙河、徒水河、龙滚河、南圣河、九 曲江等) (水温: $24-34^{\circ} \mathrm{C}$, 平均 $29^{\circ} \mathrm{C}$; $\mathrm{pH}$ : 6.5-8.9, 平 均7.3)、33个池塘(水温: $25-33^{\circ} \mathrm{C}$, 平均 $30^{\circ} \mathrm{C} ; \mathrm{pH}$ : 6.3-8.7, 平均7.3)、 21 个溪流(水温: $21-33^{\circ} \mathrm{C}$, 平均 $29^{\circ} \mathrm{C} ; \mathrm{pH}: 6.1-8.4$, 平均 7.1)、 50 个水稻田(水温: $26-35^{\circ} \mathrm{C}$, 平均 $31^{\circ} \mathrm{C} ; \mathrm{pH}: 6.2-8.7$, 平均6.9)和 14 个小 型临时水体(水温: $25-35^{\circ} \mathrm{C}$, 平均 $30^{\circ} \mathrm{C} ; \mathrm{pH}: 6.3-8.7$, 平均7.1)的样品。采样点分布详见图1。

样品带回实验室进行鉴定: 在载玻片上滴1滴 $10 \%$ 的甘油，用毛细管吸出待鉴定个体置于甘油中, 盖上四角粘有橡皮泥的盖玻片(防止挤压轮虫组织), 参考Segers (1995)和Chittapun等(2003)的方法在显 微镜下鉴定种类; 同时将各种类制作成永久性装片, 在显微描图仪下按一定比例进行绘图。

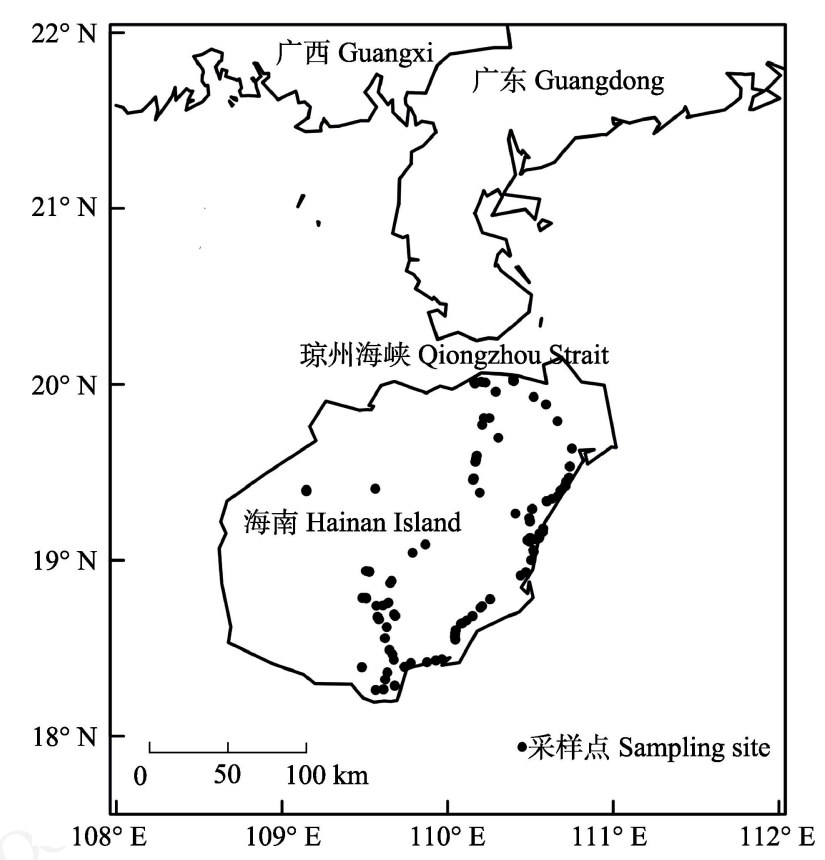

图1 海南岛腔轮虫采样点示意图

Fig.1 Map of Hainan Island with position of Lecane sampling sites 
分析海南岛腔轮虫的地理分布特征时, 参照 Segers (1996)将轮虫分为广生性种、北极-温带种、 全热带种和泛热带种 4 类。其中, 广生性种指在热 带、亚热带、温带和寒带均有出现的种类; 北极温带种指分布在北极和温带地区的种类; 全热带种 指分布于热带和亚热带地区的种类, 但在温带地区 较为适宜的生境中也有分布; 泛热带种指分布在南 北回归线之间热带地区的种类。此外，还有一些间 断分布种类，指分布于两个或更多相互分离区域的 同类生物。

采用Jaccard和Sørensen相似性系数分析海南岛 与同处东洋界的东南亚各国及我国华南地区腔轮 虫种类组成的相似程度。Jaccard相似性系数的计算 公式为: $\frac{c}{a+b+c}($ Chao et al, 2005), Sørensen相似 性系数的计算公式为: $\frac{2 c}{a+b+2 c}$ (Chao et al, 2005), 其中 $a 、 b$ 分别为 2 个样本各自独有的物种数, $c$ 为 2 个 样本共有的物种数。泰国腔轮虫数据来自Chittapun 和 Pholpunthin (2001)、Chittapun 等 (2002，2003, 2007)、Sanoamuang等(1995)、Sanoamuang (1996)、 Sanoamuang 和 Savatenalinton (1999)、Segers 和 Pholpunthin (1997)、Segers 和 Chittapun (2001)、 Segers等 (2004); 柬埔寨腔轮虫数据来自Bērzinś (1973)、Meas和Sanoamuang (2008); 越南腔轮虫数 据来自Zhdanova (2011); 老挝腔轮虫数据来自 Sergers和Sanoamuang (2007); 我国华南地区腔轮虫 数据来自Zhuge等(1998)和林秋奇等(2005)。

\section{2 结果}

本调查在海南岛共检出腔轮虫42种和 1 个亚种, 种类组成及其分布的生境详见表 1 。除了新月腔轮 虫(Lecane lunaris) 有 3 个变型外, 其他轮虫种类没有 出现形态变异。在各种类型生境中, 水稻田检出种 类最多(37种), 其次为池塘(29种)和河流(26种), 水 库(11种)、溪流(8种)和临时水体(9种)则比较少。每 个采样点检到的腔轮虫种类数为 $0-14$ 种, 最高出现 于海口东营镇一水稻田。在 134 个样品中, $25 \%$ 没有 检到腔轮虫; $50 \%$ 腔轮虫种类数为3-7种; $17 \%$ 腔轮 虫种类数超过 7 种。

囊形腔轮虫(L. bulla)、尖角腔轮虫(L. hamata)、 尾片腔轮虫( L. leontina)、月形腔轮虫( L. luna)、新
月腔轮虫、凹顶腔轮虫 (L. papuana)、梨形腔轮虫 (L. pyriformis)和四齿腔轮虫( L. quadridentata)在海南岛 各个地区及各类型生境均有分布，并且在超过 $20 \%$ 的采样点检到, 最为常见。唐纳腔轮虫 (L. donneri)、 坤杜里腔轮虫 (L. kunthuleensis)、道里沙腔轮虫 ( $L$. doryssa)、马氏腔轮虫(L. margalefi)、暗小腔轮虫 ( $L$. pusilla)、褶皱腔轮虫( L. rhytida)、玫瑰腔轮虫( $L$. rugosa)、柔弱腔轮虫( L. subtilis)、忝氏腔轮虫 ( $L$. thienemanni)和波纹腔轮虫( L. undulata)在海南岛分 布非常罕见, 均分别只在 1 个采样点检到。本次调查 共检出中国新记录种 9 种(附录1), 即唐纳腔轮虫、优 美腔轮虫(L. elegans)、坤杜里腔轮虫、侧生腔轮虫 (L. lateralis)、马氏腔轮虫、暗小腔轮虫、褶皱腔轮 虫、柔弱腔轮虫和波纹腔轮虫, 其中优美腔轮虫和 侧生腔轮虫分别在 8 个和 4 个采样点中检到。东洋界 新记录种 4 种, 即柔弱腔轮虫、马氏腔轮虫、玫瑰腔 轮虫和尖爪腔轮虫 (L. cornuta); 东洋界特有种 1 种, 即坤杜里腔轮虫。

到目前为止, 在海南岛共记录到腔轮虫49种和 1 个亚种, 种类组成包括广生性 18 种、全热带 20 种、 泛热带 5 种、北极-温带种 1 种和间断分布种 6 种。在 中国的新记录种中, 泛热带种类3种(优美腔轮虫、 坤杜里腔轮虫和侧生腔轮虫)、全热带种类5种(唐纳 腔轮虫、暗小腔轮虫、褶皱腔轮虫、柔弱腔轮虫和 波纹腔轮虫)和间断分布种 1 种 (马氏腔轮虫)。海南 岛与同处东洋区的东南亚各国和我国华南地区(广 东省)腔轮虫Jaccard和Sørensen相似性系数计算结 果表明: 海南岛与东南亚各国及我国华南地区腔轮 虫种类组成存在不同程度的差异, 最高 Jaccard和 Sørensen指数分别只有 0.436 和 0.607 (表 2 )。相对而 言, 海南岛与东南亚的泰国种类组成相似性程度高 于与我国华南地区的种类相似性程度。海南岛与华 南地区腔轮虫Jaccard和Sørensen指数分别只有 0.298 和 0.459 。

\section{3 讨论}

诸葛燕(1997)、Koste和Zhuge (1996)在1995年 调查了海南岛的腔轮虫种类多样性, 共发现了 31 种 和1亚种，其中14种是海南岛常见种类，18种(亚种) 是罕见种类。本次调查共检到腔轮虫 42 种和1亚种, 其中 16 种是海南岛常见种类, 27 种(亚种)是海南岛 罕见种类。本次调查检到的腔轮虫种类数量比 
表1 海南岛腔轮属种类组成。 Re: 水库; Ri: 河流; P: 池塘; B: 溪流; Rf: 水稻田; T: 临时水体。

Table 1 List of Lecane from Hainan Island, China. Habitat is given by $\mathrm{Re}=$ reservoir, $\mathrm{Ri}=$ river, $\mathrm{P}=$ pond, $\mathrm{B}=$ brook, $\mathrm{Rf}=$ rice field, $\mathrm{T}=$ temporary pond.

\begin{tabular}{|c|c|c|c|}
\hline 种类 Species & 生境 Habitat & 本研究 This study & 1995 (Zhuge, 1997) \\
\hline 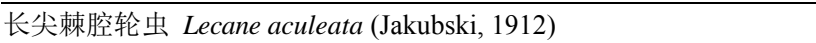 & Re, Ri, P & + & - \\
\hline 尖棘腔轮虫 L. arcula Harring, 1914 & Re, Ri, Rf, P & + & - \\
\hline 弓形腔轮虫 L. arcuata (Bryce, 1891) & $\mathrm{Rf}$ & + & + \\
\hline 愉悦腔轮虫 L. aspasia Myers, 1917 & $\mathrm{Ri}, \mathrm{Rf}$ & + & - \\
\hline 囊形腔轮虫 L. bulla (Gosse, 1851) & Re, Ri, Rf, P, B, T & + & + \\
\hline 尖趾腔轮虫 L. closterocerca (Schmarda, 1859) & Rf, P, B & + & + \\
\hline 尖爪腔轮虫 L. cornuta (Müller, 1786) & Ri, Rf, B, P & + & - \\
\hline 鞋型腔轮虫 L. crepida Harring, 1913 & $\mathrm{Re}, \mathrm{P}$ & + & + \\
\hline 弯角腔轮虫 L. curvicornis (Murray, 1913) & Rf, Ri, P, B & + & + \\
\hline 暖昧腔轮虫 L. decipiens (Murray, 1913) & Ri, T & - & + \\
\hline 唐纳腔轮虫 L. donneri Chengalath \& Mulamoottil, 1974 & $\mathrm{Rf}$ & + & - \\
\hline 道里沙腔轮虫 L. doryssa Harring, 1914 & $\mathrm{Rf}$ & + & - \\
\hline 优美腔轮虫 L. elegans Harring, 1914 & Rf, $P$ & + & - \\
\hline 爱沙腔轮虫 L. elsa Hauer, 1931 & Rf, Ri, P, B & + & + \\
\hline 柔㓞腔轮虫 L. flexilis (Gosse, 1886) & $\mathrm{P}$ & - & + \\
\hline 叉爪腔轮虫 L. furcata (Murray, 1913) & Re, Rf, Ri, P, T & + & + \\
\hline 大腔轮虫 L. grandis (Murray, 1913) & Ri, Rf, P & + & + \\
\hline 短棘腔轮虫 L. haliclysta Harring \& Myers, 1926 & $\mathrm{Ri}$ & - & + \\
\hline 尖角腔轮虫 L. hamata (Stokes, 1896) & Ri, Rf, Re, P & + & + \\
\hline 矛趾腔轮虫 L. hastata (Murray, 1913) & Rf, Ri, P & + & + \\
\hline 突纹腔轮虫 L. hornemanni (Ehrenberg, 1834) & Rf, Ri, P, T & + & + \\
\hline 无甲腔轮虫 L. inermis (Bryce,1892) & Rf, Ri, P, T & + & + \\
\hline 并趾腔轮虫 L. inopinata Harring \& Myers, 1926 & $\mathrm{P}$ & - & + \\
\hline 坤杜里腔轮虫 L. kunthuleensis Chittapun, Pholpunthin \& Segers, 2003 & $\mathrm{Ri}$ & + & - \\
\hline 侧生腔轮虫 L. lateralis Sharma, 1978 & Rf, $P$ & + & - \\
\hline 尾片腔轮虫 L. leontina (Turner, 1892) & Rf, Ri, P & + & - \\
\hline 罗氏腔轮虫 L. ludwigii (Eckstein, 1883) & Rf, $P$ & + & + \\
\hline 月形腔轮虫 L. luna (Müller, 1776) & Re, Rf, Ri, P, T & + & + \\
\hline 新月腔轮虫 L. lunaris (Ehrenberg, 1832) & Re, Rf, Ri, B, P & + & + \\
\hline 长趾新月腔轮虫 L. lunaris f. acus (Harring, 1913b) & Re, $P$ & + & + \\
\hline 前缢新月腔轮虫 L. lunaris f. constricta (Murray, 1913c) & $\mathrm{Re}, \mathrm{Ri}$ & + & + \\
\hline 钝爪新月腔轮虫 L. lunaris f. crenata (Murray, 1913b) & Re, Ri, P & + & + \\
\hline 马氏腔轮虫 L. margalefi De Manuel, 1994 & $\mathrm{Rf}$ & + & - \\
\hline 矮小腔轮虫 L. nana (Murray, 1913) & $\mathrm{P}$ & - & + \\
\hline 凹顶腔轮虫 L. papuana (Murray, 1913) & Re, Rf, Ri, P, B & + & + \\
\hline 暗小腔轮虫 L. pusilla Harring, 1914 & $\mathrm{Rf}$ & + & - \\
\hline 梨形腔轮虫 L. pyriformis (Daday, 1905) & Rf, Ri, P, B, T & + & + \\
\hline 四齿腔轮虫 L. quadridentata (Ehrenberg, 1832) & Rf, Ri, P & + & + \\
\hline 莱茵腔轮虫 L. rhenana Hauer, 1929 & $\mathrm{Re}, \mathrm{P}$ & + & - \\
\hline 禇皱腔轮虫 L. rhytida Harring \& Myers, 1926 & $\mathrm{Rf}$ & + & - \\
\hline 罗伯腔轮虫 L. robertsonae Segers, 1993 & $\mathrm{P}$ & - & + \\
\hline 玫瑰腔轮虫 L. rugosa (Harring, 1914) & $\operatorname{Re}$ & + & - \\
\hline 盾形腔轮虫 L. scutata (Harring \& Myers, 1926) & $\mathrm{P}$ & + & + \\
\hline 显志腔轮虫 L. signifera (Jennings, 1896) & Rf, Ri, P, T & + & + \\
\hline 长圆显志腔轮虫 L. signifera ploenensis (Voigt, 1902) & Rf, B & + & + \\
\hline 史氏腔轮虫 L. stenroosi (Meissner, 1908) & Rf, Ri, P, T & + & + \\
\hline 无爪腔轮虫 L. styrax (Harring \& Myers, 1926) & $\mathrm{P}$ & - & + \\
\hline 柔弱腔轮虫 L. subtilis Harring \& Myers, 1926 & $\mathrm{Rf}$ & + & - \\
\hline 细趾腔轮虫 L. tenuiseta Harring, 1914 & Rf, Ri, P & + & + \\
\hline 忝氏腔轮虫 L. thienemanni (Hauer, 1938) & $\mathrm{Ri}$ & + & + \\
\hline 波纹腔轮虫 L. undulata Hauer, 1938 & $\mathrm{Rf}$ & + & - \\
\hline 爪趾腔轮虫 L. unguitata (Fadeew, 1925) & Rf, Ri, P, T & + & + \\
\hline 蹄形腔轮虫 L. ungulate (Gosse, 1887) & Rf, Ri & + & - \\
\hline
\end{tabular}


表2 海南岛腔轮虫与东洋界其他国家和地区的Jaccard相似性系数(对角线以上)和Sørensen相似性系数(对角线以下)

Table 2 Jaccard similarity index (above diagonal) and Sørensen similarity index (below diagonal) of Lecane between Hainan Island and other country or region of the Oriental zone

\begin{tabular}{lllllll}
\hline & $\begin{array}{l}\text { 中国海南 } \\
\text { Hainan, China }\end{array}$ & $\begin{array}{l}\text { 中国广东 } \\
\text { Guangdong, China }\end{array}$ & $\begin{array}{l}\text { 泰国 } \\
\text { Thailand }\end{array}$ & $\begin{array}{l}\text { 柬埔寨 } \\
\text { Cambodia }\end{array}$ & $\begin{array}{l}\text { 越南 } \\
\text { Vietnam }\end{array}$ & $\begin{array}{c}\text { 老挝 } \\
\text { Laos }\end{array}$ \\
\hline $\begin{array}{l}\text { 中国海南 Hainan, China } \\
\text { 中国广东 Guangdong, China }\end{array}$ & 0.459 & 0.298 & 0.436 & 0.406 & 0.179 & 0.377 \\
泰国 Thailand & 0.607 & & 0.202 & 0.333 & 0.280 & 0.351 \\
柬埔寨 Cambodia & 0.578 & 0.337 & & 0.427 & 0.134 & 0.354 \\
越南 Vietnam & 0.303 & 0.500 & 0.598 & & 0.263 & 0.535 \\
老挝 Laos & 0.548 & 0.438 & 0.237 & 0.417 & & 0.235 \\
\hline
\end{tabular}

1995 年高出 $26 \%$, 其中有 18 个种在 1995 的调查中 并没有记录(表 1)。在这些海南岛新记录种中，除了 尖爪腔轮虫、蹄形腔轮虫(L. ungulata)和尾片腔轮虫 在超过 $20 \%$ 的采样点中检到外，其他种类均在海南 岛非常罕见。1995 年的调查结果中的暧昧腔轮虫 $(L$. decipiens)、柔韧腔轮虫(L. flexilis)、短棘腔轮虫 $(L$. haliclysta)、并趾腔轮虫 (L. inopinata)、矮小腔轮虫 (L. nana)、罗伯腔轮虫 (L. robertsonae) 和无爪腔轮虫 (L. styrax)等 7 种在本次调查中并没有检到, 而且它 们均是海南岛的罕见种类。对比两次的调查结果可 知, 两次调查中常见种类组成并没有太大差别, 仅 相差 2 种, 种类组成及多样性差异主要来自罕见种 类。上述情形的出现与两次调查覆盖的空间范围和 采样点数量的差别比较大有一定的关系。诸葛燕 (1997)在 1995 年的调查只采集了 40 个样点, 并且集 中在海口、琼海和三亚 3 个地方; 本次采样点有 134 个, 遍布海南岛东线和中线各个地区, 以及西线城 市儋州市; 生境包含水库和池塘等静水水体、河流 和小溪的急流带、滞留带、河道带等流水水体以及 水稻田和水坑等临时性水体。总体上讲, 两次调查 的结果基本反映了海南岛腔轮虫的种类多样性, 但 不排除还有一些稀有种类尚没有被检到。

目前全球已知腔轮虫199种和 2 个亚种(Segers, 2007)。我国动物地理区划属于世界动物地理分区的 古北界和东洋界。Zhuge等(1998)报道了中国共有腔 轮虫 59 种和 2 个亚种。本次调查增加了中国新记录 种9种, 因此, 到目前为止, 中国共有腔轮虫 68 种和 2 个亚种, 约占全球已知腔轮虫种类的 $35 \%$ 。海南岛 属于东洋界, 现有腔轮虫记录 49 种和 1 个亚种, 约 占我国腔轮虫种类的 $72 \%$, 其中 14 种仅在海南岛有 记录, 腔轮虫多样性不仅远高于我国处于古北界的
各地区，也远高于同处东洋界的华南地区(Zhuge et al, 1998; 林秋奇等, 2005)。一般而言, 热带地区腔轮虫 种类多样性明显高于温带地区(Dumont, 1983; Segers, 1996，2001)。海南岛位于我国的南端，是我国真正 意义上的热带地区，而华南地区主要属于亚热带地 区，因而海南岛高的腔轮虫种类多样性体现了热带 地区的轮虫分布特征。与同处东洋界的东南亚各国 相比, 海南岛腔轮虫种类多样性仅次于泰国(81种), 但高于柬埔寨(36种)、越南(12种)和老挝(30种)。

广生性种、北极-温带种、全热带种和泛热带 种这 4 个类群的轮虫在海南岛均有分布。但是, 海南 岛腔轮虫主要由广生性、全热带和泛热带种组成, 北极-温带种类只有 1 种(盾形腔轮虫)。此外, 海南岛 还有一些间断分布的腔轮虫种类。在这些间断分布 种类中, 尖爪腔轮虫广泛分布在古北界、新北界和 新热带界(Segers，1995), 在东洋界只有零星记录; 爱沙腔轮虫 (L.elsa) 主要分布于古北界和新北界 (Segers, 1995), 目前在东洋界只是在我国的海南岛 和广东省有记录(Koste \& Zhuge, 1996; 林秋奇等, 2005); 玫瑰腔轮虫主要分布于新热带界, 在古北界 和澳洲界也有零星报道(Segers, 2007), 本次调查是 首次在东洋界发现该种的分布; 马氏腔轮虫由 De Manuel (1994)首次发现于西班牙马略卡岛，并被认 为是该地的特有种，本调查是在第二个地理分区发 现该种的分布。在 9 种中国新记录种中，除了马氏腔 轮虫和柔弱腔轮虫是首次在东洋界发现外, 其他7 种均在东洋界已有报道(Segers, 2007)。坤杜里腔轮 虫的首次报道是在泰国南部的一个泥炭沼泽中 (Chittapun et al, 2003), 本次调查是第二次报道该种 在东洋界的分布, 它属泛热带种类, 但在海南岛比 较罕见, 仅在保亭县徒水河岸边水生高等植物间发 
现，其头孔腹面略凹，而泰国种类头孔腹面完全平 直; 优美腔轮虫和侧生腔轮虫属泛热带种类; 柔弱 腔轮虫属全热带种类, 主要分布于旧热带界、古北 界、新北界和新热带界, 本次调查只在海口澄沟水 稻田的 1 个样品中发现; 唐纳腔轮虫、暗小腔轮虫、 褶皱腔轮虫和波纹腔轮虫属全热带种类。虽然海南 岛地处热带地区, 而新记录种基本上是泛热带或全 热带种类, 但它们在海南岛并不常见。

理论上讲, 海南岛地史上与大陆这种连、断、 再连、再断的变化有助于海南岛与华南地区频繁的 物种交流。但是, 从腔轮虫的种类组成上看, 海南 岛与华南地区的差异性比较大, Jaccard和Sørensen 相似性系数分别只有 0.298 和 0.459 。华南地区腔轮 虫由广生性种类和全热带种类组成, 而且在华南地 区分布的腔轮虫种类在海南岛均有分布, 而在海南 岛有分布的泛热带种类、部分全热带种类在华南地 区没有分布。虽然海南岛与华南地区存在物种交流, 但由于两个地区的气候差异, 导致海南岛上一些热 带种类无法在华南地区生存。海南岛与泰国虽然在 地史上未曾相连, 但由于均处热带地区, 种类组成 相似程度反而高于与华南地区的相似程度。

\section{参考文献}

Bērzinś B (1973) Some rotifers from Cambodia. Hydrobiologia, 41, 453-459.

Chao A, Chazdon RL, Colwell RK, Shen TJ (2005) A new statistical approach for assessing similarity of species composition with incidence and abundance data. Ecology Letters, 8, 148-159.

Chen YH, Bi JF (2007) Biogeography and hotspots of amphibian species of China: implications to reserve selection and conservation. Current Science, 92, 480-489.

Chittapun S, Pholpunthin P (2001) The rotifer fauna of peat-swamps in southern Thailand. Hydrobiologia, 446/447, 255-259.

Chittapun S, Pholpunthin P, Segers H (2002) Rotifer diversity in a peat-swamp in southern Thailand (Narathiwas Province) with the description of a new species of Keratella Bory de St. Vincent. Annales de Limnologie, 38, 185-190.

Chittapun S, Pholpunthin P, Segers H (2003) Contribution to the knowledge of Thai microfauna diversity: notes on rare peat swamp Rotifera, with the description of a new Lecane Nitzsch, 1872. Hydrobiologia, 501, 7-12.

Chittapun S, Pholpunthinb P, Segers H (2007) Diversity of rotifer fauna from five coastal peat swamps on Phuket Island, southern Thailand. Science Asia, 33, 383-387.

De Manuel J (1994) Taxonomic and zoogeographic considera- tions on Lecanidae (Rotifera: Monogononta) of the Balearic Archipelago, with description of a new species, Lecane margalefi n. sp. Hydrobiologia, 288, 97-105.

Dumont HJ (1983) Biogeography of rotifers. Hydrobiologia, 104, 19-30.

Koste W, Zhuge Y (1996) A preliminary report on the occurrence of rotifer in Hainan. Quekett Journal of Microscopy, 37, 666-683.

Lin QQ, Zhao SY, Han BP (2005) Rotifer distribution in tropical reservoirs, Guangdong Province, China. Acta Ecologica Sinica, 25, 1123-1131. (in Chinese with English abstract) [林秋奇, 赵帅营, 韩博平 (2005) 广东省水库轮虫分布 特征. 生态学报, 25, 1123-1131.]

Meas S, Sanoamuang L (2008) Rotifer communities in the Cambodian Mekong River Basins. Khon Kaen University Research Journal (GS), 8, 18-30.

Myers N, Mittermeier RA, Mittermeier CG, Da Fonseca GA, Kent J (2000) Biodiversity hotspots for conservation priorities. Nature, 403, 853-858.

Sanoamuang L, Segers H, Dumont HJ (1995) Additions to the rotifer fauna of south-east Asia: new and rare species from north-east Thailand. Hydrobiologia, 313/314, 35-45.

Sanoamuang L (1996) Lecane segersi n. sp. (Rotifera, Lecanidae) from Thailand. Hydrobiologia, 339, 23-25.

Sanoamuang L, Savatenalinton S (1999) New records of rotifers from Nakhon Ratchasima Province, northeast Thailand, with a description of Lecane baimaii n. sp. Hydrobiologia, 412, 95-101.

Segers H (1995) Rotifera, Vol. 2: The Lecanidae (Monogononta). Guides to the Identification of the Microinvertebrates of the Continental Waters of the World. 6. SPB Academic Publishing BV.

Segers H (1996) The biogeography of littoral Lecane rotifera. Hydrobiologia, 323, 169-197.

Segers H, Pholpunthin P (1997) New and rare Rotifera from Thale-Noi Lake, Pattalang Province, Thailand, with a note on the taxonomy of Cephalodella (Notommatidae). Annales de Limnologie, 33, 13-21.

Segers H (2001) Zoogeography of the Southeast Asian Rotifera. Hydrobiologia, 446/447, 233-246.

Segers H, Chittapun S (2001) The interstitial rotifera of a tropical freshwater peat swamp on Phuket Island, Thailand. Belgian Journal of Zoology, 131, 65-71.

Segers H, Kotethip W, Sanoamuang L (2004) Biodiversity of freshwater microfauna in the floodplain of the River Mun, Northeast Thailand: the Rotifera monogononta. Hydrobiologia, 515, 1-9.

Segers H (2007) Annotated checklist of the rotifers (Phylum Rotifera), with notes on nomenclature, taxonomy and distribution. Zootaxa, 1564, 1-104.

Sergers H, Sanoamuang L (2007) Note on a highly diverse rotifer assemblage (Rotifera: Monogononta) in a Laotian rice paddy and adjacent pond. International Review of 
Hydrobiology, 92, 640-646.

Yan JA (2006) Paleontology and ecologic environmental evolution of the Quaternary in Hainan Island. Journal of Palaeogeography, 8, 103-115. (in Chinese with English abstract) [颜家安 (2006) 海南岛第四纪古生物及生态环境 演变. 古地理学报, 8, 103-115.]

Zhdanova SM (2011) The species composition of rotifers in the water reservoirs of central Vietnam. Inland Water Biology, 4, 425-434.

Zhuge Y (1997) Studies on Taxonomy and Distribution of Rotifera in Typical Zones of China. PhD dissertation, Institute of Hydrobiology, Chinese Academy of Sciences, Wuhan. (in Chinese with English abstract) [诸葛燕 (1997) 中国典型 地带轮虫的研究. 博士学位论文, 中国科学院水生生物 研究所, 武汉.]

Zhuge Y, Huang XF, Koste W (1998) Rotifera recorded from China, 1893-1997, with remarks on their composition and distribution. International Review of Hydrobiology, 83, 217-232, 415-429.

(责任编委: 徐奎栋 责任编辑: 间文杰)

\section{附录 Supplementary Material}

附录1 海南岛腔轮虫的中国新记录种示意图

Appendix 1 Diagram of Lecane species that as new to China on Hainan Island http://www.biodiversity-science.net/fileup/PDF/2016359-1.pdf 


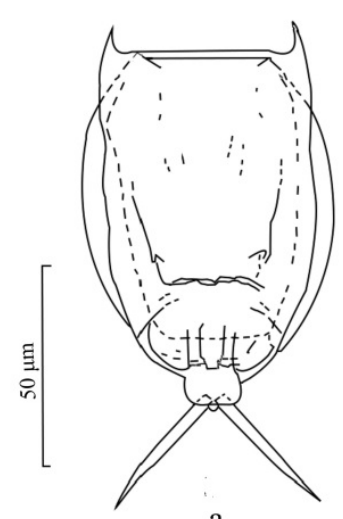

a

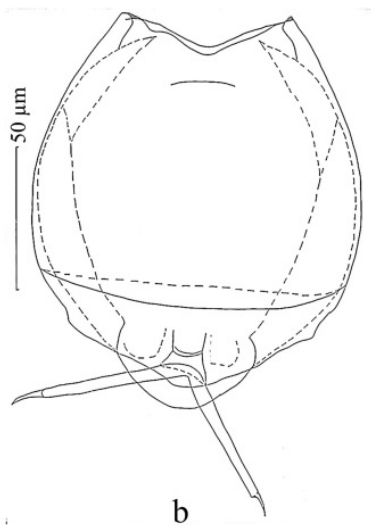

b
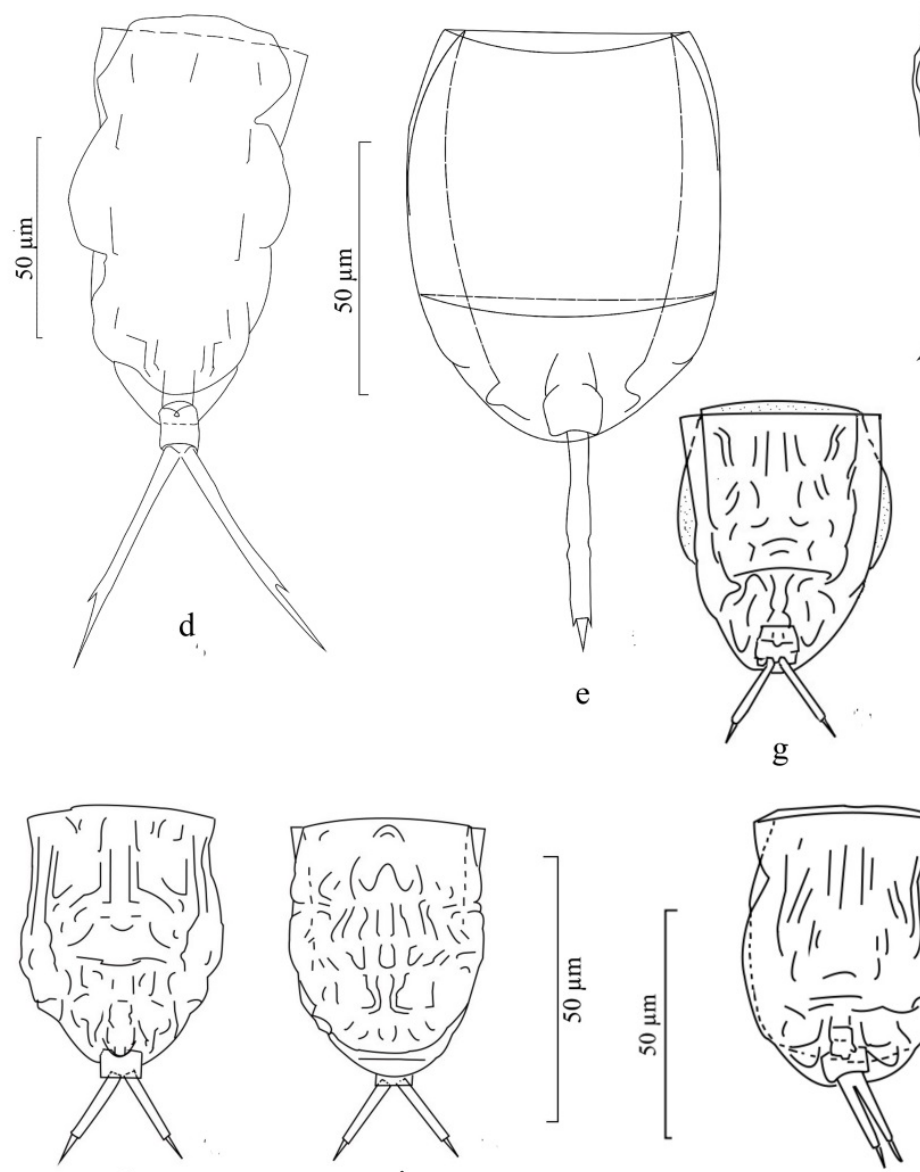

i

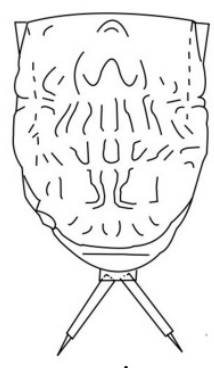

$\mathrm{j}$

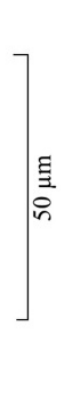

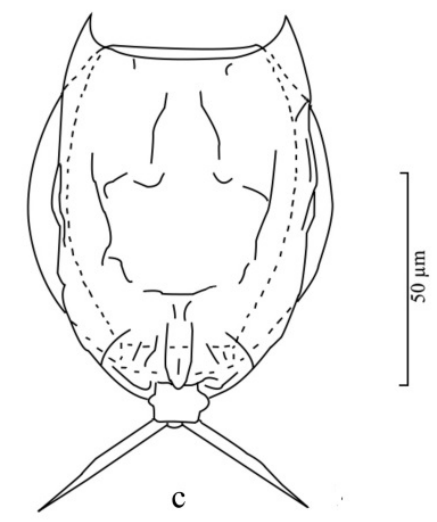
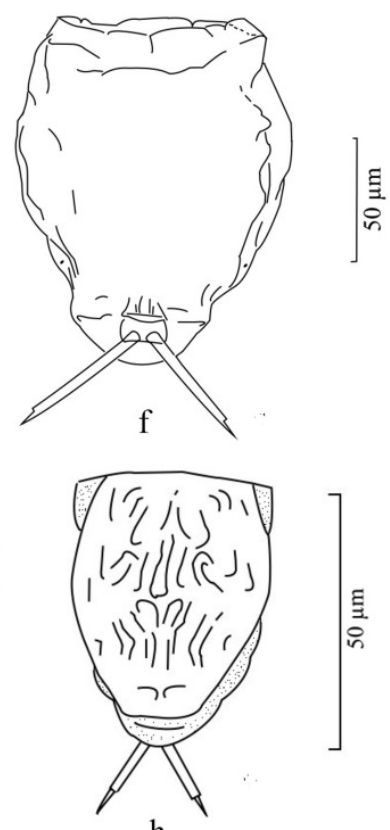

$\mathrm{h}$

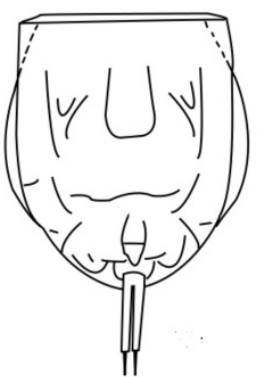

1

附录1 海南岛腔轮虫的中国新记录种示意图. a: 唐纳腔轮虫; b: 侧生腔轮虫; c: 褶皱腔轮虫; d: 优美腔轮虫; e: 坤杜 里腔轮虫; f: 马氏腔轮虫; g: 暗小腔轮虫腹面观; $h:$ 暗小腔轮虫背面观; i: 柔弱腔轮虫腹面观; j: 柔弱腔轮虫背面观; $k$ : 波纹腔轮虫腹面观; $1:$ 波纹腔轮虫背面观

Appendix 1 Diagram of Lecane species that as new to China on Hainan Island. a, L. donneri; b, L. lateralis; c, L. rhytida; d, $L$. elegans; e, L. kunthuleensis; f, L. margalefi; g, the ventral view of L. pusilla; h, the dorsal view of L. pusilla; i, the ventral view of $L$. subtilis; j: the dorsal view of $L$. subtilis; $\mathrm{k}$, the ventral view of $L$. undulata; l: the dorsal view of $L$. undulate. 